\title{
General Medicine-Based Quality Electronic Clinical Record
}

\section{Turabian JL*}

Department of Family and Community Medicine, Health Center Santa Maria de Benquerencia, Spain

*Corresponding author: Jose Luis Turabian, Specialist in Family and Community Medicine, Health Center Santa Maria de Benquerencia, Toledo, Spain, Email: jturabianf@hotmail.com

\section{Mini Review}

Volume 1 Issue 1

Received Date: November 23, 2018

Published Date: December 05, 2018

DOI: $10.23880 /$ jqhe- 16000105

\section{Abstract}

The most common form of narration or biography of the disease consists of the clinical history and the annotations of the clinicians. The increasing availability of data stored in electronic health records brings substantial opportunities for advancing patient care and population health. But still there is a challenge in electronic health record in general medicine. Electronic health records for general medicine should be based on the concepts of this specialty, and the use of the tool should promote the tendency to routinely use the basic elements of general medicine. In this way, the desirable characteristics of electronic health records in general medicine are: 1) Clinical usability; 2) That is not electronic health records a barrier to communication and doctor-patient relationship; 3) Narrative; 4) Relational; 5) Flexible; 6) Decentralized base, at least in part; 7) That electronic health records show the multiplicity of chronological times; 8) Multiplicity of techniques; 9) Oriented to the context; and 10) Clinical decision support. This implies technological characteristics such as: a) free text; b) allow visualization in graphic form of multiple patient connections; c) a patient image on a timeline, to which a collection of objects can be added on screen; d) presence of clinical notes, interviews, transcriptions of audio tapes, diaries personal, video recordings, etc; e) a visualization in grid or by biological, psychological and social planes, f) and finally, the possibility that the individual himself can cooperate in his history, which also maintains and controls in part.

Keywords: Family Physician; Family Practice; Communication; Education, Medical; Electronic Health Records; Medical Record; Physician-Patient Relations; Physician's Role; Family Medical History; Personal Health Records; History Taking Medical

Abbrevations: CR: Clinical Record; eCR: Electronic Clinical Records; GPs: General Practitioners.

\section{Introduction}

The most common form of narration or biography of the disease consists of the clinical history and the annotations of the clinicians that constitute the clinical record (CR). This CR is the official text of the disease experience. The CR is produced collaboratively (even if it is difficult or implicit), and therefore it is a shared product, between doctor and patient. To speak of CR is an old problem and always new in the professional task. The CR can be studied according to two criteria not easily 


\section{Journal of Quality in Health Care \& Economics}

differentiated: its form and its content. Without a constant allusion to the art of diagnosis, to the classification of ailments and to the theory of disease, it is not possible to understand the structure, content and intention of a CR [1].

The application of new information and communication technologies to the healthcare world, including clinical history, constitutes an extraordinary progress. Today we cannot continue organizing care services like fifteen years ago, and it is urgent to bet on electronic clinical records (eCR) to approach patients and manage the knowledge generated by the millions of healthcare events that occur daily [2].

But, health professionals know since time immemorial that the information obtained from a patient will be different depending on where the attention is placed. And what characterizes an excellent $\mathrm{CR}$ in general medicine/family medicine? The elements of a CR in general medicine/family medicine that define it as excellent are those that allow it to be used by different professionals without detriment to information, but that contains the highly useful elements for the diagnosis, treatment and rehabilitation of the patient from the Basic criteria of general medicine/family medicine [3-5]. Although there is a disparity of CR models that derive from different approaches to the understanding of the nature of medicine, these models essentially have a common point: they register diseases of the organs of people who seem to live in isolation and do not have psychosocial or cultural context $[6,7]$. In this sense, the basic or crucial concepts that clinical history should have in general medicine have been described [8].

That is, some of the potential benefits of having an eCR are obvious and no one doubts the usefulness of computer science, but many question some of its applications, especially in family medicine [9-12]. The eCR implies an important iatrogenic potential. On the one hand, obvious, affect the communication between general practitioners (GPs) and patients $[13,14]$. But they also contain serious underlying problems, especially in family medicine, which are perhaps, more important because their influence is much less obvious and has much more devastating longterm effects a potential iatrogenic on the very concepts of general medicine/medicine of family [15-18]. Using electronic patient records create a particular process of writing and reading [19]. So that could make GPs forget and stop practicing the fundamental elements of general medicine, and this specialty will be another type of medical care different, since the technological instrument would give rise to a different practice, which would come to be learned and perpetuated [7].

In this scenario, the aim of this article is, from these fundamental concepts of general medicine, to describe and systematize the elements that should be supported by technology of eCR in general medicine, which should differentiate it from practice of other medical specialties.

\section{Discussion}

Despite the expense, frustration, and slow implementation of eCR, some GPs still believe in "ideal imagined electronic records systems." But, as there is little evidence of benefits in patient outcome, confidentiality concerns remain, rigidity of electronic records has been underestimated, etc., for most GPs this is a case of an "emperor with no clothes" [20]. Although a large number of general practitioners may think so, in fact, the message in Hans Christian Andersen fairy tale, "The Emperor's New Clothes," is that "It does not have to be true what everyone thinks that is true " [21]. In this way, we think, perhaps against the majority, that a series of concepts that define the eCR of general medicine can be proposed and systematized. These desirable characteristics of eCR in general medicine are proposed in Table 1.

\begin{tabular}{|c|c|}
\hline 1 & Clinical usability \\
\hline 2 & $\begin{array}{c}\text { Prevent it from being a barrier to communication } \\
\text { and doctor-patient relationship }\end{array}$ \\
\hline 3 & Narrative \\
\hline 4 & Relational \\
\hline 5 & Flexible \\
\hline 6 & Decentralized base \\
\hline 7 & That it shows the multiplicity of chronological \\
\hline 8 & times \\
\hline 9 & That it shows the multiplicity of techniques \\
\hline 10 & Context-oriented \\
\hline
\end{tabular}

Table 1: Desirable Quality Characteristics of the Electronic Clinical Register In General Medicine.

\section{Clinical “Usability"}

The eCR face the task of ensuring that the presentation of the information remains usable and effective [22]. Many attempts to get GPs to use electronic health records have failed, often because of difficulties with data entry. Technology should complement and improve clinical care, not impose extra burdens on already overloaded medical staff [14]. Family doctors work with "case histories" and they must address realities such as the patient's 


\section{Journal of Quality in Health Care \& Economics}

understanding of the medical condition. The clinical "usability" of eCRs is particularly relevant as it affects patient care. An eCR system may enhance the ability of physicians to complete information intensive tasks but can make it more difficult to focus attention on other aspects of patient communication [19,23]. Another problem that hinders the "usability" of the eCRs is the recording by episodes, which forces the general practitioner to disintegrate the integral attention in its multiple components, assigning each one of them to its corresponding "episode" with its respective code, all this to generate a kind of information of null reliability that is not used; it is perfect for banal consultations, but useless in a complex query. In addition, eCRs may imply that primary care physicians receive too many notifications that interrupt and fragment their work [24].

\section{That is not a Barrier to Communication and Doctor-Patient Relationship}

Computer use can indeed affect the communication between GPs and patients. As the use of a computer requires time and attention from GPs, this may well interfere with the communication process. Yet, the information accessed on the computer may also enhance communication. Therefore, GPs ought to remain aware of their computer use during consultations and at the same time keep the interaction with the patient alive [13]. That is to say, the use of eCRs can exert both positive and negative impacts on physician-patient relationships. The negative impacts can be overcome by some simple means as better designs of eCR systems and medical education interventions [25].

\section{Narrative}

Many eCRs system are rejected by GPs because they are not based on a narrative metaphor. Using the screen as a sheet of paper, with free text, it would make the clinical history more a sociological than a cognitive process. The potential benefits of having an eCR are obvious, mainly for structured and codified data, but not for a free text, which is how the GP works.

Clinicians should be able to enter their data as free text, which should be coded by natural language processing in real time making it immediately usable for other computation, such as alerts. In addition, the narrative data should be annotated and structured with temporal relationships, severity, causal connections, clinical explanations and rationale. GPs value the importance of describing an evocative clinical picture with a written text, and eCR codes can constrain clinical language. Writing about the patient confers on medical practice a kind of understanding that is not obtainable in any other way. Structured narrative should be the potential to facilitate capturing of data from clinicians by allowing freedom of expression, giving immediate feedback, supporting reuse of clinical information and structuring data for subsequent processing, such as quality assurance and clinical research [26-32].

\section{Relational}

Relationships with significant persons, or forms of group interaction, can influence a large number of health outcomes. What is traditionally called individual, family and community attention are elements of the same reality, and cannot be separated. The eCRs should allow the GP to have a "panoramic view" in real time: see the patient in two ways: 1) from the verticality of the individual who consults with their health problem and their personal history, and 2) from the horizontality of their family group and their relationships [33-35]. This should allow the visualization, even graphically, of the multiple connections of that patient, which give rise to sequences of causes in which the person both creates the systems in which they are immersed, as they are transformed by them. The eCR should be able to graphically show the network or matrix of patient relationships (such as diagram, or "ladder" etc).

It would not be a question of relating "everything to everything"; in the same way that to describe a living organism is not to specify each molecule in it, and catalog or classify it piece by pieces (by organs ...), but we have to know its "pattern" or significant set. In the eCR is accurate know the "critical variables" of the patient in order to go through links in "activated words" to other places: pathobiography, family, treatments, previous episodes, etc. Likewise, it could be considered that the patient can cooperate in his eCR, which also maintains and even controls, although the possibility has been communicated that patients with online access to their eCRs can use more services and it implies modifying the medical jargon to make it accessible to the patient [36-39].

\section{Flexible}

The potential benefits of having eCR are obvious, but a Health Center situation "without papers" is not necessarily good or desirable. Flexible options should be allowed. For example, avoiding rigid options, such as not allowing prescriptions to patients for more than a certain time, forcing more frequent appointments with the patient than the clinic can advise, or avoiding structured forms for data entry, where the user has to select relevant clinical term from a predefined list, since in this 


\section{Journal of Quality in Health Care \& Economics}

restrictive system unconscious changes in the meaning of the codified can occur [40].

\section{Decentralized Base}

The single and centralized eCR can be the most expensive solution, technologically less advanced and more risky, compared to the most respectful as the shared eCRs and decentralized bases, with greater accessibility and power, without the problems and social costs of the first one [41,42]. Very little of the information that is required and collected in a general medicine consultation is relevant (convenient, adequate, timely) for the rest of the health levels. In addition, not all relevant information is remarkable, valuable, important or transcendental. Further, the centralized and unique clinical history model leads us to the issue of confidentiality $[42,44]$.

In the centralized eCRs, the general practitioner loses all control over the clinical records that he himself has made (a physical failure in the lines from the database means that there is no record) and there are possibilities of technological limitations with a macro base: slowness, traffic jams, etc. There is the possibility of a Block chain implementations system, where there may be "blocks" that maintain a certain amount of information to describe a specific patient (or procedure), although other part of the health care information would be kept out of the chain of blocks, centrally [45].

\section{That Shows the Multiplicity of Chronological Times}

The disease always imposes a time backwards: we walk forward with our eyes turned towards the past [46]. The eCR should have a presentation like that of a computer game: an image of the patient on a timeline, to which a collection of on-screen objects can be added, such as clinical observations, indications of studies and treatments, etc., and that show us back the previous evolution, and the interaction with other contacts (family, work ...) registered. In this way, in the eCR, each fact and each phenomenon, it could be operated taking into account its past history (in its various historical periods) so that this previous evolutionary history can explain the present. For example, the eCR could be reread on a temporary basis, trying to find "force lines" that can explain the present.

Continuity of care is one of the defining characteristics of family medicine. It is at this level of health care where the opportunity to study the natural history of the disease is more easily presented to professional. The GPs work includes to knowing the natural history of the health problems and the individual and family life cycle, and thus, he or she is in an optimal place to observe from the family history, the final consequences of any health problem [47-49].

\section{Multiplicity of Techniques}

In general medicine there is an emphasis on the importance of qualitative methods -the history of life- for the knowledge of the patient [50]. The continuum of information for the knowledge of the narration of the disease, can include a multiplicity of qualitative techniques, in addition to the narration and the history of life, such as, clinical notes, semi-structured or structured interviews, transcriptions of audio tapes, diaries personal, video recordings, photographs, etc. The eCR must allow and facilitate the realization of registration, and easy and quick use of all these techniques.

\section{Context Oriented}

The key conceptual elements in the context-oriented eCR are: 1) the categorization of health problems within a global context (bio psychosocial) of the patient, and 2) the multiplicity of actors involved- For the eCR, an easy access to the list of problems and Family mapping marks the most superficial difference between the contextualization or not of the patient [51,52]. One could think of a software that included these variables, possibly with a technical solution of hypertext, with writing and images, and the use of areas or "active" words that are colored with certain colors according to the characteristics of those variables (different colors for actors, resources, contexts, etc.), relevant for that patient, which are superimposed as transparent sheets of a notebook or "windows" on the screen, so that different levels are displayed at the same time, or colors that are they mix like in the palette of a painter, and the interconnections are represented by the structure of the different colors, and that allow to "click" or "link" on them to access other windows, and that it is possible to connect the eCRs of diverse people who are connected by these contextual variables (for example, "linking" resources with actors that own them, actors with connected actors, etc.), quickly in real time as a help in the process of diagnosis and therapeutic decision.

Another very important point is the bio psychosocial vision. It is also possible to think of a computerized solution of the "patient evaluation grid" (Table 2). Examining this grid helps prioritize treatment plans; for example, factors of the present context such as intense anxiety, may require immediate treatment before the etiological treatment. There can be computer 


\section{Journal of Quality in Health Care \& Economics}

developments that could generate these grills in the eCR

$[53,54]$.

\begin{tabular}{|c|c|c|c|}
\hline \multirow[t]{2}{*}{ Dimensions } & \multicolumn{3}{|c|}{ Contexts } \\
\hline & Current context & Recent context & Background context \\
\hline Biological & $\begin{array}{l}\text { - Symptoms and } \\
\text { physical signs -Exam } \\
\text { physical } \\
\text { - Current laboratory } \\
\text { and image values }\end{array}$ & $\begin{array}{l}\text { - Start and change of } \\
\text { symptoms and signs } \\
\text { - Changes of the physical } \\
\text { situation Changes of medications } \\
\text { - } \quad \text { Use of drugs }\end{array}$ & $\begin{array}{l}\text { History of disease } \\
\text { Family disease history }\end{array}$ \\
\hline Psychological & $\begin{array}{l}\text { - } \quad \text { Reason for } \\
\text { consultation Mental situation } \\
\text { - Expectations of } \\
\text { treatment } \\
\text { - } \quad \text { The current doctor- } \\
\text { patient relationship }\end{array}$ & 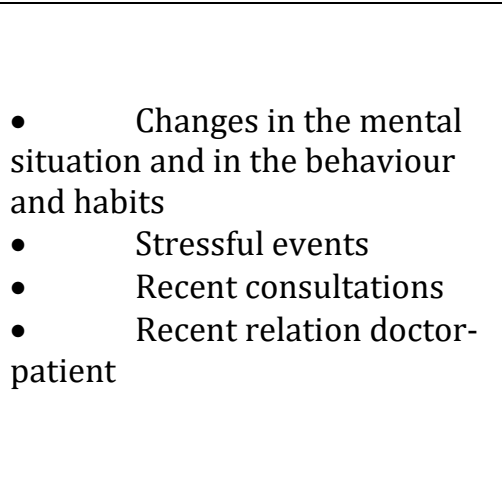 & $\begin{array}{ll}\text { - } & \text { Personality traits } \\
\text { - } & \text { Mechanisms of } \\
\text { defense and coping with the } \\
\text { disease } \\
\text { - } & \text { Attitude to the disease } \\
\text { - } & \text { Habits } \\
\text { - } & \text { History psychiatric } \\
\text { past } & \\
\text { - } & \text { Relation doctor- } \\
\text { patient previous } \\
\text { - } & \text { Health resources }\end{array}$ \\
\hline Social & $\begin{array}{l}\text { - } \quad \text { Genogram (who lives } \\
\text { with the patient) } \\
\text { - } \quad \text { Occupation } \\
\text { - } \quad \text { Stress } \\
\text { - } \quad \text { Physical } \\
\text { environment }\end{array}$ & $\begin{array}{l}\text { - Changes in living } \\
\text { conditions } \\
\text { - } \quad \text { Changes in work } \\
\text { - } \quad \text { Changes in the physical } \\
\text { environment }\end{array}$ & $\begin{array}{lc}- & \text { Job of parents and } \\
\text { socioeconomic class } \\
\text { - } & \text { Ethnicity, religion, } \\
\text { gender } & \text {... History school } \\
\bullet & \text { First relations } \\
\text { - } & \text { Marriage Family } \\
\text { interactions (Genogram) } \\
\text { - } & \text { Health resources }\end{array}$ \\
\hline
\end{tabular}

Table 2: Patient Evaluation Grid.

Finally, the eCR should facilitate the visualization and connection of the patient with the three levels of community resources: 1.The inventory of individual capacities: specific skills, talents, interests, experiences, etc. 2.The inventory of organizations, associations and formal and informal groups; and 3.The inventory of local institutions that have a more formal structure with resources for the production of goods and services. [55].

\section{Decision Support}

Still accepting this "narrative" basic element of the clinical encounter, however, the eCRs should improve clinical care via clinical decision support, electronic guideline-based reminders and alerts, using representative and clinical evidence data. Anyway, not all studies support the ability of health information technology to fundamentally alter outpatient care quality $[11,56]$.

\section{Conclusions}

The eCRs introduces a "third party" into exam room interactions: doctor-patient (and family or companion) and computer. Students, trainees, and GPs should learn to integrate eCRs into triadic consulting room interactions [57]. The most common form of narration or biography of the disease consists of the clinical history and the annotations of the clinicians; it is the official text of the experience of the disease. The eCRs for general medicine should be based on the concepts of this specialty, and the use of this electronic tool should promote the tendency to routinely use the basic elements of general medicine [58].

In this way, the desirable characteristics of the eCR in general medicine are: 1 . Clinical "usability", avoiding that in the eCR a paper-and-pencil bureaucracy is substituted by another one of mouse clicks; 2 . That the eCR be not a barrier to communication and doctor-patient 


\section{Journal of Quality in Health Care \& Economics}

relationship; 3. Structured narrative, which should have the potential to facilitate capture of data from clinicians by allowing freedom of expression, giving immediate feedback, supporting reuse of clinical information and structuring data for subsequent processing, such as quality assurance and clinical research; 4 . Relational; 5 . Flexible; 6. Decentralized base or with a Block chain system, where there are "blocks" that maintain a small amount of specific information, although another part of the information is centralized; 7. That eCR shows the multiplicity of chronological times; 8. A eCR with multiplicity of techniques; 9. An eCR oriented to the context; and 10. With clinical decision support. Table 3 exposes the technological characteristics that are suggested, as a consequence of the proposed eCR model.

\begin{tabular}{|c|c|}
\hline \multicolumn{2}{|r|}{ Technological Characteristics of the Electronic Clinical Records } \\
\hline 1 & Free text \\
\hline 2 & $\begin{array}{l}\text { Allow visualization of the multiple connections of the patient in a graphic way, perhaps through hyperlinks that } \\
\text { allow to go, through links in activated words or "critical variables" of the patient, to other places to visualize the } \\
\text { network or matrix of relationships (such as diagram, or "ladder", etc.): pathobiography, family, treatments, } \\
\text { previous episodes, etc. }\end{array}$ \\
\hline 3 & Informative graphics, at least, about genogram and family life cycle \\
\hline 4 & $\begin{array}{l}\text { Presentation similar to that of a computer game: an image of the patient on a timeline, to which a collection of } \\
\text { objects can be added on screen: clinical observations, indications, studies, treatments, etc., showing the } \\
\text { previous evolution and the interaction with contacts (family, work ...) }\end{array}$ \\
\hline 5 & $\begin{array}{l}\text { The continuum of information for the knowledge of the narration of the disease which include clinical notes, } \\
\text { interviews, transcriptions of audio tapes, personal diaries, video recordings, etc. }\end{array}$ \\
\hline 6 & $\begin{array}{l}\text { A display in a grid or biological, psychological and social planes, such as transparent sheets of a notebook or } \\
\text { "windows" on the screen, so that the different levels can be visualized at the same time }\end{array}$ \\
\hline 7 & Help to improve clinical care via clinical decision support and electronic guideline-based reminders and alerts \\
\hline 8 & $\begin{array}{l}\text { Allow the possibility that the individual himself can cooperate in their history, which also maintains and } \\
\text { controls in part }\end{array}$ \\
\hline
\end{tabular}

Table 3: Technological Characteristics of the Electronic Clinical Records.

\section{References}

1. Laín Entralgo P (1998) The clinical history: history and theory of the pathographic story/Pedro Laín Entralgo.

2. Alonso López FA, Cristos CJ, Larumbe AB, Molina FG, Perruca AS, et al. (2000) Computerization in primary care (I). Aten Primaria 26(7): 434-511.

3. Turabian JL, Perez Franco B (2010) Family medicine clinical sessions: they do exist! Aten Primaria 42(12): 588-590.

4. Turabian JL, Pérez FB (2010) The diagnostic concept in family medicine: see a landscape. The diagnosis in family medicine. Aten Primaria 42(2): 63-128

5. Turabian JL, Pérez FB (2010) The concept of treatment in family medicine: A contextualized and contextual map of a city hardly seen. Aten Primaria 42(5): 253-304.
6. Bonardi FR (1991) The clinical history Your practical methodology. Argentine Publications Diffuser, Buenos Aires.

7. Turabián Fernández JL, Pérez Franco B (2004) La historia clínica electrónica: ¿comer sopa con tenedor? Cuadernos de Gestión 10(4): 175-88.

8. Turabian JL (2018) Twelve Commandments for General Medicine Clinical Record: Some Suggestions That Are Not in the Text books. Archives of Community and Family Medicine 1(2): 21-29.

9. Stiglic G, Kocbek P, Fijacko N, Sheikh A, Pajnkihar M (2017) Challenges associated with missing data in electronic health records: A case study of a risk prediction model for diabetes using data from Slovenian primary care. Health Informatics J.

10. Joos D, Chen Q, Jirjis J, Johnson KB (2006) An Electronic Medical Record in Primary Care: Impact on Satisfaction, Work Efficiency and Clinic Processes. AMIA Annu Symp Proc, pp: 394-398. 


\section{Journal of Quality in Health Care \& Economics}

11. Romano MJ, Stafford RS (2011) Electronic Health Records and Clinical Decision Support Systems Impact on National Ambulatory Care Quality. Arch Intern Med 171(10): 897-903.

12. Erin Walkinshaw (2011) Challenges of family practice: using electronic records. CMAJ 183(12): 1354-1355.

13. Noordman J, Verhaak $P$, van Beljouw I, van Dulmen S (2010) Consulting room computers and their effect on general practitioner-patient communication. Fam Pract 27: 644-651.

14. Walsh SH (2004) The clinician s perspective on electronic health records and how they can affect patient carre. BMJ 328: 1184.

15. Turabian JL (2017) A Short Collection of Fables for Learning the Fundamental Principles of Family Medicine: Chapter 1. Comprehensiveness, Continuity, Contextualization and Family. Ann Fam Gen Pract 1(2): 32-39.

16. Turabian JL (2018) Some Basic Concepts of Family Medicine Explained by Means of Fables (Part 2 of 2): Patient-Centered Interview, Biopsicosocial Model, Actors and Resources/Strengths of the Patients, and Concept of Health and Disease. Archives of Community and Family Medicine 1(1): 10-18.

17. Turabian JL, Perez-Franco B (2016) The Family Doctors: Images and Metaphors of the Family Doctor to Learn Family Medicine. J Gen Pract 4(5): 1-3.

18. Turabian JL (1995) Family and community medicine notebooks: an introduction to the principles of family medicine $1^{\text {st }}$ (Edn.), Ediciones Díaz de Santos, pp: 576.

19. Laitinen H, Kaunonen M, Åstedt-Kurki P (2014) The impact of using electronic patient records on practices of reading and writing. Health Informatics J 20(4): 235-249.

20. Bewley S, Fawdry R, Cummings G, Perry H (2010) Electronic health records. The naked truth. BMJ 341: c4564.

21. The Emperor's New Clothes.

22. Sharda P, Das AK, Patel V (2003) Specifying Design Criteria for Electronic Medical Record Interface Using Cognitive Framework. AMIA Annu Symp Proc, pp: 594-598.

23. Makoul G, Curry RH, Tang PC (2001) The Use of Electronic Medical Records. Communication Patterns in Outpatient Encounters. J Am Med Inform Assoc 8(6): 610-615.

24. Murphy DR, Meyer AND, Russo E, Sittig DF, Wei L, et al. (2016) The Burden of Inbox Notifications in Commercial Electronic Health Records. JAMA Intern Med 176(4): 559-560.

25. Shachak A, Reis S (2009) The impact of electronic medical records on patient-doctor communication during consultation: a narrative literature review. J Eval Clin Pract 15(4): 641-649.

26. Johnson SB, Bakken S, Dine D, Hyun S, Mendonça E, et al. (2008) An Electronic Health Record Based on Structured Narrative. J Am Med Inform Assoc 15(1): 54-64.

27. Hurwitz B (2000) Narrative and the practice of medicine. Lancet 356(9247): 2086-2089.

28. Donnelly JW (2002) Patients' Stories as Narrative. JAMA 287(4): 447-448.

29. Charon R (2007) What to do with stories. The sciences of narrative medicine. Can Fam Physician 53(8): 1265-1267.

30. Turabian JL, Franco BP (2017) Responses to Clinical Questions: Specialist-Based Medicine vs. Reasonable Clinic in Family Medicine. Integr J Glob Health 1: 1.

31. Lazaro J (2014) "La medicina narrativa" El paciente llega a la consulta con un gran relato (su vida) y el final es la enfermedad actual. OPINIÓN, Babelia.

32. Aronson JK (2000) Autopathography: the patient s tale. BMJ 321: 1599.

33. Tange HJ (1999) Consultation of medical narratives in the electronic medical record. Method Inf Med 38(45): 289-293.

34. Bonn D (2001) Biocomplexity: look at the whole, not the parts. Lancet 357(9252): 288.

35. Martín Serrano M, Piñuel Raigada JL, Gracia Sanz J, Arias Fernández MA (1982) Teoría de la comunicación. I. Epistemología y análisis de referencia. Cuadernos de la Comunicación de la Facultad de Ciencias de la Información de la Universidad Complutense de Madrid. Madrid: A. Corazón.

36. Boscolo L (1999) Del síntoma individual al emergente familiar. Área 3(7): 29-32. 


\section{Journal of Quality in Health Care \& Economics}

37. Harries-Jones P (1995) Ecological understanding and Gregory Bateson. University of Toronto Press, pp: 358.

38. Palen TE, Ross C, Powers JD, Xu S (2012) Association of online patient access to clinicians and medical records with use of clinical services. JAMA 308(19): 2012-2019.

39. Bates DW, Wells S (2012) Personal health records and health care utilization. JAMA 308(19): 20342036.

40. Wang CJ (2012) Medical Documentation in the Electronic Era. JAMA 308(20): 2091-2092.

41. Birtwhistle RV, Godwin MS, Delva MD, Casson RI, Lam $M$, et al. (2004) Randomized equivalence trial comparing three month and six month follow up of patients with hypertension by family practitioners. BMJ 328(7433): 204.

42. Alonso López FA, Custodi I Canosa J (2001) Strategic models for the design of electronic medical records. Medifam 11(6): 313-320.

43. Coiera E (2011) Do we need a national electronic summary care record? Med J Aust 194(2): 90-92.

44. Júdez J, Nicolás P, Delgado MT, Hernando P, Zarco J, et al. (2002) Confidentiality in clinical practice: clinical history and information management 118(1): 18-37.

45. Zoutman DE, Ford BD, Bassili AR (2004) The confidentiality of patient and physician information in pharmacy prescription records. CMAJ 170(5): 815816.

46. Pirtle C, Ehrenfeld J (2018) Blockchain for Healthcare: The Next Generation of Medical Records? J Med Syst 42(9): 172.

47. De Brasi M (1999) Entre dos tiempos: nacimiento y procreación. Área 3(7): 33-7.

48. Turabian JL (2017) Stories Notebook about the Fundamental Concepts in Family Medicine: Continuity, The Fable of The River with Meanders. J Gen Pract 5(1): 1-2.
49. Turabian JL (2017) A Narrative Review of Natural History of Diseases and Continuity of Care in Family Medicine. Arch Community. Med Public Health 3(1): 41-47.

50. Turabian JL (2017) Opportunistic Prevention in Family Medicine: Anticipatory Care, Case-Finding and Continuity of Care. J Health Care Prev 1(1): 1-4.

51. Goldman R, Hunt MK, Allen JD, Hauser S, Emmons K, et al. (2003) The life history interview method: applications to intervention development. Health Educ Behav 30(5): 564-581.

52. Charlton R (1995) Balancing science and art in primary care research: past and present. $\mathrm{Br}$ J Gen Pract 45(401): 639-640.

53. Douglas J (1992) How to get the most from your doctor. Bloomsbury, London.

54. Stewart M, Brown JB, Weston WW, McWhinney IR, McWilliam CL, et al. (1995) Patient-centered medicine. Transforming the clinical method. BMJ 311: 1580.

55. Turabian JL, Perez Franco B (2008) Individual care with community orientation. Contextualized care 1-5.

56. Turabian JL, Perez Franco B (2001) Community Activities in Family Medicine and Primary Care. a new practical approach $1^{\text {st }}$ (Edn.), Ediciones Díaz de Santos 1: 768.

57. Coronado GD, Petrik AF, Vollmer WM, Taplin SH, Keast EM, et al. (2018) Effectiveness of a mailed colorectal cancer screening outreach program in community health clinics: The STOP CRC cluster randomized clinical trial. JAMA Intern Med 178(9): 1174-1181.

58. Lown BA, Rodriguez D (2012) Commentary: Lost in translation? How electronic health records structure communication, relationships, and meaning. Acad Med 87(4): 392-394. 